\title{
Laser Printing of Three-Dimensional Multicellular Arrays for Studies of Cell-Cell and Cell-Environment Interactions
}

\author{
Martin Gruene, ${ }^{1, *}$ Michael Pflaum, ${ }^{2, *}$ Christian Hess, Ph.D., ${ }^{2}$ Stefanos Diamantouros, ${ }^{3}$ \\ Sabrina Schlie, Ph.D., ${ }^{1}$ Andrea Deiwick, ${ }^{1}$ Lothar Koch, Ph.D., ${ }^{1}$ Mathias Wilhelmi, M.D., ${ }^{2}$ \\ Stefan Jockenhoevel, M.D., ${ }^{3}$ Axel Haverich, M.D., ${ }^{2}$ and Boris Chichkov, Ph.D.
}

Utilization of living cells for therapies in regenerative medicine requires a fundamental understanding of the interactions between different cells and their environment. Moreover, common models based on adherent twodimensional cultures are not appropriate to simulate the complex interactions that occur in a three-dimensional (3D) cell-microenvironment in vivo. In this study, we present a computer-aided method for the printing of multiple cell types in a 3D array using laser-assisted bioprinting. By printing spots of human adipose-derived stem cells (ASCs) and endothelial colony-forming cells (ECFCs), we demonstrate that (i) these cell spots can be arranged layer-by-layer in a 3D array; (ii) any cell-cell ratio, cell quantity, cell-type combination, and spot spacing can be realized within this array; and (iii) the height of the 3D array is freely scalable. As a proof of concept, we printed separate spots of ASCs and ECFCs within a 3D array and observed cell-cell interactions in vascular endothelial growth factor-free medium. It has been demonstrated that direct cell-cell contacts trigger the development of stable vascular-like networks. This method can be applied to study complex and dynamic relationships between cells and their local environment.

\section{Introduction}

T HE FUNDAMENTAL UNDERSTANDING of cell responses to environmental cues is a key issue in biomedicine for the repair of tissue disorders. These stimuli are manifold and can have physical, mechanical, chemical, and biological backgrounds. Further, the dynamic cell response to these external signals occurs in real time and is therefore challenging to assess.

The necessity of making these cell responses predictable and meeting the requirements of multiple experiments in parallel led to the development of cellular microarrays., ${ }^{1,2}$ This technique enables studying the effects of drugs, 3,4 extracellular matrix (ECM) proteins, ${ }^{5}$ growth factors, ${ }^{6,7}$ and biomaterials $^{8,9}$ in a low-cost and high-throughput manner. Despite the impressive results that were obtained with twodimensional (2D) cell arrays, these conventional procedures lack the ability to predict cell behavior in a three-dimensional (3D) culture, because cellular response to environmental signals is context dependent and significantly differs from traditional 2D adherent cell cultures. ${ }^{10-12}$ Thus, 3D cell array platforms that retain cells in hydrogel cultures were developed. This development marks an important step toward cell-based assays that can predict in vivo behavior more accurately because of the high water content and mechanical properties of the 3D hydrogel environment, resembling those of native tissue. ${ }^{13,14}$ However, all of the aforementioned cell arrays cannot be used to study cell-cell interactions, because cells are seeded as mono- or cocultures without controlled cell arrangement.

Controlled geometrical deposition of cells within 3D cellular arrays can be achieved by dielectrophoretic forces ${ }^{15}$ or optical traps ${ }^{16}$ with subsequent photopolymerization of the applied hydrogel. However, these techniques are limited by the poor ability to control the deposition of ECM components and by the use of photoreactive hydrogel precursors. ${ }^{17}$ Therefore, other techniques, which enable precise positioning of different cell types in a 3D hydrogel network along with specific ECM components, are needed. Further, cell densities have to be controlled throughout the $3 \mathrm{D}$ matrix, because

\footnotetext{
${ }^{1}$ Department of Nanotechnology, Laser Zentrum Hannover e. V., Hannover, Germany.

${ }^{2}$ Department of Cardiothoracic, Transplantation, and Vascular Surgery, Hannover Medical School, Hannover, Germany.

${ }^{3}$ Department of Tissue Engineering and Textile Implants, Institute of Applied Medical Engineering, Helmholtz Institute of the RWTH Aachen University, Aachen, Germany.

*These two authors equally contributed to this work.
} 
variation of cell amounts in mono- and cocultures plays an important role during tissue maturation. ${ }^{18-20}$ Further development of printing devices to dispense cells in a nondetrimental and computer-controlled manner provides possibilities to address these issues. Several different techniques were adapted to print living cells along with varying hydrogel precursors, such as inkjet ${ }^{21-26}$ and extrusion- ${ }^{27,28}$ and laser-based techniques. ${ }^{29,30}$

Among these different printing approaches, laser-assisted bioprinting (LaBP), based on laser-induced forward transfer, possesses the capability to print (i) cell amounts ranging from single ${ }^{31}$ to tens of cells per droplet, ${ }^{32}$ (ii) hydrogel precursors with a wide range of rheological properties, 33,34 and (iii) cells with micrometer resolution in a highthroughput manner without any observable damage to genotype and phenotype. ${ }^{35-39}$ The LaBP setup consists of a pulsed laser source, a donor slide from which the biologic material (cell solution) is printed, and a collector slide receiving the printed cell droplets. Cell transfer occurs as a result of rapid laser pulse energy deposition, which leads to a jet formation. ${ }^{40}$ The influence of different process parameters on the jet behavior are not yet fully investigated, but recent studies demonstrate that the printed volume can be adjusted by the rheologic properties of the applied hydrogel precursor (e.g., viscosity) and the laser pulse energy. ${ }^{33,34,38,41}$ By changing the initial cell density on the donor slide, different numbers of cells can be transferred per single laser pulse. ${ }^{37,38}$ The printing speed (number of printed droplets per second) depends on the laser pulse repetition rate and can be in the range of a few megahertz. These high printing speeds will be needed for high-throughput assembly of cell arrays to study multiple cell responses in parallel.

In this study, LaBP is applied for 3D assembly of multicellular arrays to investigate cell-cell and cell-environment interactions. A natural hydrogel consisting of a fibrin precursor and hyaluronic acid served as the cell carrier and environmental material. We demonstrate that different cell amounts, cell-cell ratios, and distances between the cell droplets can be realized within the 3D cell array. The following strategy was applied: (i) first, a layer of fibrin is produced on the collector slide by blade-coating of the fibrin precursor and subsequent crosslinking; (ii) different cell types are printed on the top of the first fibrin layer at a controlled cell spot-spacing by LaBP; (iii) a second fibrin layer is blade-coated using the same procedure. Last, the second and third steps can be repeated several times to produce true 3D cell arrays. To demonstrate the feasibility of this method, 3D arrays consisting of human adipose-derived stem cells (ASCs) and human endothelial colony-forming cells (ECFCs), printed in separated spots with a controlled proximity to each other, are generated. With the help of these 3D arrays, it is observed that direct cell-cell contacts trigger the development of stable vascular-like networks in vitro.

\section{Materials and Methods}

\section{Preparation of the hydrogel precursors}

The fibrinogen (human plasma, plasminogen free; SigmaAldrich) was dissolved in purified water (milliQ ${ }^{\mathrm{TM}}$; Millipore). Then, it was dialyzed against Tris-buffered saline (TBS) using 6.000 MW tubing (Novodirect) overnight. The fibrinogen concentration following sterile filtration was estimated by measuring absorbance at $280 \mathrm{~nm}$ with a spectrophotometer (Spectronic Genesys ${ }^{\mathrm{TM}}$ 6; Thermo Fisher Scientific GmbH). The final concentration of the fibrinogen solution was adjusted to $20 \mathrm{mg} / \mathrm{mL}$ with sterile TBS. Afterward, viscosity of the final solution was adjusted by mixing $1 \mathrm{wt} \%$ hyaluronic acid (rooster comb, neutralized pH 7.4; Sigma-Aldrich) in the ratio of $1: 2(\mathrm{v} / \mathrm{v})$ with the fibrinogen precursor. The final hydrogel, referred to as HA-fibrinogen, has a fibrinogen concentration of $13.3 \mathrm{mg} / \mathrm{mL}$ and a zero shear viscosity of $120 \mathrm{mPa}$ s (Fluids Spectrometer RFS II; Rheometrics Scientific).

Bovine thrombin $(40 \mathrm{U} / \mathrm{mL}$; Sigma-Aldrich) was mixed with TBS and $50 \mathrm{mM} \mathrm{CaCl} 2$ in the ratio of 1:3:1 (v:v:v) and stored at $4^{\circ} \mathrm{C}$ before use.

\section{Isolation and culture of cord blood-derived late-outgrowth ECFCs}

ECFCs were purified from human umbilical cord blood obtained from healthy newborn donors after informed parental consent. Mononuclear cells (MNCs) were isolated from the heparinized cord blood by Ficoll density gradient centrifugation. MNCs were seeded on $1 \%$ gelatin-precoated plastic plates at a density of $10^{5}$ cells $/ \mathrm{cm}^{2}$. The cells were cultured in endothelial growth medium (endothelial cell basal medium [Lonza] with $10 \%$ fetal calf serum [FCS] and growth factor supplements containing vascular endothelial growth factor [VEGF], epidermal growth factor, fibroblast growth factor [FGF-2], insulin growth-like factor, hydrocortisone, ascorbic acid, heparin, and penicillin/streptomycin). Culture plates were scored for the presence of endothelial cell colonies starting 5 days after the onset of culture. With the appearance of adherent endothelial cell clusters with cobblestone-like morphology at 1-2 weeks of culture, the cells were adapted to endothelial cell growth mediun-2 containing 2\% FCS. On reaching 70\% confluence, human ECFCs were trypsinized and reseeded at a density of $0.8 \times 10^{3}$ cells $/ \mathrm{cm}^{2}$. The endothelial phenotype of cells was verified using flow cytometry and RT-PCR as previously described. $^{42}$

\section{Isolation and culture of human ASCs}

Purification of ASCs was performed as previously reported. ${ }^{39}$ Briefly, the lipoaspirate was digested with $0.1 \%$ collagenase solution (type CLS; Biochrom AG) at $37^{\circ} \mathrm{C}$ for $45 \mathrm{~min}$. After centrifugation at $450 \mathrm{~g}$, the cell pellet was filtered through $100 \mu \mathrm{m}$ and then $40 \mu \mathrm{m}$ nylon filters. After lysis of erythrocytes and centrifugation, the ASC-containing cell pellet was resuspended in expansion medium consisting of Dulbecco's modified Eagle's medium/F12 (PAA Laboratories) supplemented with $10 \%$ fetal bovine serum (FBS gold; PAA Laboratories), $100 \mathrm{U} / \mathrm{mL}$ penicillin, $100 \mu \mathrm{g} / \mathrm{mL}$ streptomycin, and $10 \mathrm{ng} / \mathrm{mL}$ basic FGF-2 (ITC Leibniz University Hannover). The isolated cells were transferred into culture flasks and cultured in expansion medium at $37^{\circ} \mathrm{C}$ in a humidified atmosphere containing $95 \%$ air and $5 \% \mathrm{CO}_{2}$. For the laser printing experiments, ASCs at passages 5-6 were used.

\section{Cell staining, survival, proliferation, and genotoxicity}

ASCs were stained with TAMRA-5 (25 nM; Invitrogen) and ECFCs with calcein ( $50 \mathrm{nM}$; Invitrogen) for $45 \mathrm{~min}$ at $37^{\circ} \mathrm{C}$. After the staining procedure, the cells were centrifuged at 500 $g$ for $5 \mathrm{~min}$ and washed twice with phosphate-buffered saline. 
The survival rate was addressed by measuring the viability of cells before and after the laser printing procedure (Casy TT; Roche Diagnostics $\mathrm{GmbH}$ ) from four independent prints per cell type.

Detailed information about the assessment of cell proliferation can be found in the supplemental methods of Ref. ${ }^{37}$ and about genotoxicity in Ref. $^{43}$

\section{LaBP setup}

A detailed description of the laser printing setup based on laser-induced forward transfer has been previously published. ${ }^{36}$ Briefly, two coplanar glass slides were assembled in close proximity $(500 \mu \mathrm{m})$ to each other. The upper glass slide, referred to as the donor slide, was covered with a $60 \mathrm{~nm}$ energy-absorbing gold layer using plasma-enhanced sputter deposition (Cressington 208HR; EO Service $\mathrm{GmbH}$ ) and, subsequently, a layer of the cell-containing hydrogel precursor to be transferred. The lower glass slide, referred to as the collector slide, was covered with a layer of hydrogel, which cushioned the cell impact and provided a moist environment for the cells during the printing procedure. Laser pulses were focused through the upper glass slide onto the gold layer, which was locally evaporated at the focal point. A high gas pressure was generated resulting in a jet formation $^{40}$ that propelled the subjacent cell-containing hydrogel precursor toward the collector slide. All material transfer experiments in this study were carried out under normal air conditions.

\section{Preparation of the cell solution layer on the donor slide}

Cultivated cells (ASCs and ECFCs) were trypsinized and resuspended in culture medium. Afterward, the cell concentration was determined with a cell counter (Casy TT; Roche Diagnostics $\mathrm{GmbH}$ ). Preset numbers of cells were centrifuged at $300 \mathrm{~g}$ for $5 \mathrm{~min}$ and the supernatant was removed. The cell pellet was resuspended in $45 \mu \mathrm{L}$ of HA-fibrinogen solution. The obtained cell suspension was pipetted on the gold-coated donor slide, a square glass plate with a size of $26 \mathrm{~mm}$ and a thickness of $1 \mathrm{~mm}$. The cell suspension was dispersed on the gold surface with a selfassembled blade coater to form a homogenous layer of $\sim 65 \mu \mathrm{m}$ thickness. Then, the cell-coated donor slide was fixed in a metal frame and mounted upside down in the setup.

\section{Preparation of the hydrogel layer on the collector slide}

The collector slide, a square glass plate with a size of $25.4 \mathrm{~mm}$ and $1 \mathrm{~mm}$ thickness, was sterilized in an ethanol bath, cleaned with isopropanol, and then irradiated with $\mathrm{UV}-\mathrm{C}$ radiation for $5 \mathrm{~h}$. Afterward, the collector slide was coated with $100 \mu \mathrm{L}$ of the HA-fibrinogen solution and subsequently wetted with a thrombin solution, resulting in a layer thickness of $\sim 150 \mu \mathrm{m}$. After gelation for several minutes, the coated collector slide was fixed in a metal frame and mounted in the setup facing the cell-coated donor slide in close proximity $(500 \mu \mathrm{m})$.

\section{Generation of 3D cell arrays by a fibrin-based layer-by-layer approach}

The assembly of 3D cell arrays can be generally broken down into three steps as illustrated in Figure 1. In the first step, $100 \mu \mathrm{L}$ HA-fibrinogen solution was spread onto the collector slide and blade-coated to a final layer thickness of $\sim 145 \mu \mathrm{m}$. The thrombin solution was spray-coated over the collector slide, leading to gelation into fibrin and surface wetting. Afterward, the collector slide was assembled in the setup facing the donor slide carrying the first solution with ECFCs in close proximity $(500 \mu \mathrm{m})$.

During the second step, ECFCs embedded in the HAfibrinogen solution were printed in a square array of $9 \times 9$ droplets with $800 \mu \mathrm{m}$ spacing between droplets. Afterward, another donor slide carrying ASCs was assembled in the setup and HA-fibrinogen droplets containing ASCs were printed with an internal $x / y$-shift of $400 \mu \mathrm{m}$ relative to the first droplet array, resulting in an $8 \times 8$ array of droplets. Unreacted thrombin on top of the fibrin layer induced gelation of the printed HA-fibrinogen droplets with the embedded cells and fixed them in position. Array dimension and droplet spacing were arbitrarily chosen and could be extended to any desired size.

In the third step, $100 \mu \mathrm{L}$ HA-fibrinogen solution was spread on top of the cell array and blade-coated to a final height of $\sim 290 \mu \mathrm{m}$. The complete array was spray-coated with the thrombin solution and kept in an incubator for $30 \mathrm{~min}$. These 3D cell arrays were utilized for all conducted cell experiments, because the planar cell distribution provides several advantages over free-form 3D cell arrays as reported later.

\section{Variation of the cell-cell ratio and cell amounts within the cell array}

ASCs and ECFCs were separately harvested, counted, stained with TAMRA-5 (ASCs) and Calcein AM (ECFCs), and mixed as coculture in different ratios. These cocultures with different (ECFCs to ASCs) ratios were blade-coated on the donor slides and printed in $9 \times 9$ spot arrays. As can be seen in fluorescence microscopy images shown in Figure 2A, different cell ratios per printed droplet can be easily produced.

In addition, the cell amount per spot within the cell array can be varied by printing additional droplets with known number of cells (52 \pm 14 per droplet) on top of each other (iteration loops shown in Fig. 2B). In all conducted cell experiments reported later, separated spot arrays of ECFCs (green staining) and ASCs (red staining) were printed with three iterations (three droplets with the same kind of cells per spot) as illustrated in Figure 2B.

\section{Generation of free-form 3D cell arrays by a fibrin-based layer-by-layer approach}

More complex 3D arrangements of cell spots can be achieved by iterations of steps 2 and 3 shown in Figure 1. To illustrate this, ASCs and ECFCs were stained with fluorescent dyes, printed in spot arrays separated with fibrin layers, and imaged by laser scanning microscopy (see Fig. 3). The ECFCs (green staining) were printed in a $9 \times 9$ spot array with $800 \mu \mathrm{m}$ spot spacing on top of the first HA-fibrin layer and subsequently embedded into a second HA-fibrinogen layer blade-coated on top of it. Then, the ASCs (red staining) were printed in an $8 \times 8$ spot array with an $x / y$-shift of $400 \mu \mathrm{m}$, with respect to the first cell array, and embedded into a third HA-fibrinogen layer. After that, the ECFCs 
Step 1: Application of the first layer

Step 3: Application of the second layer
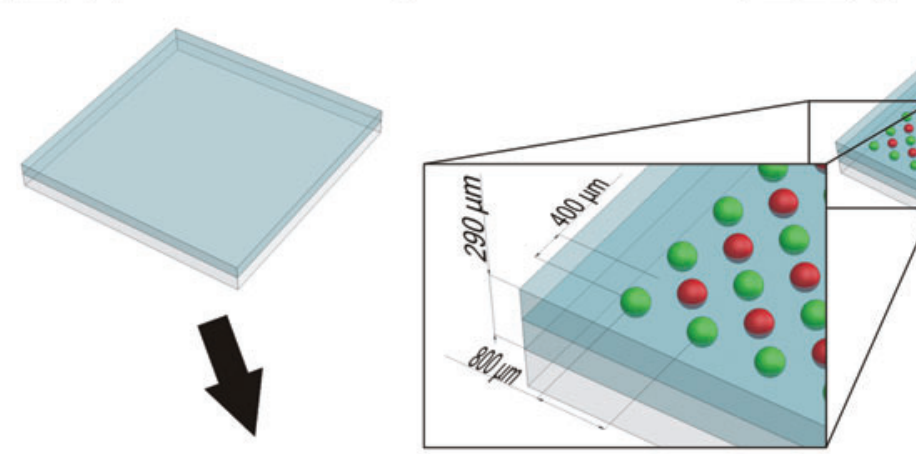

Step 2: Laser printing of the cell-hydrogel compound

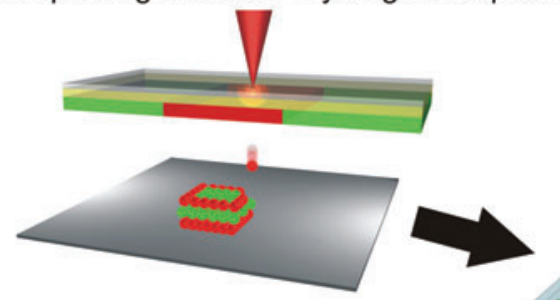

\section{First cell-type}

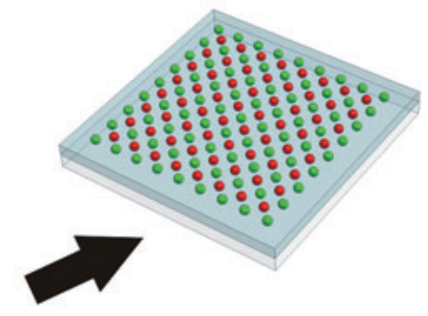

Second cell-type

FIG. 1. Schematic illustration of the generation of cell arrays by LaBP. Step 1: The first HA-fibrinogen layer is blade-coated on the collector slide and subsequently wetted with the crosslinking agent; Step 2: The first (green spots) and second (red spots) cell types are printed in separated spot arrays at a defined distance to each other by means of LaBP; Step 3: The second HA-fibrinogen layer is blade-coated on top of the cell array and subsequently wetted by a crosslinking agent. LaBP, laserassisted bioprinting. Color images available online at www.liebertonline.com/tec

(green staining) were printed again in an $8 \times 8$ spot array with an $x$-shift of $400 \mu \mathrm{m}$, with respect to the first cell array, and embedded into the last blade-coated HA-fibrinogen layer. This 3D cell array, consisting of four HA-fibrin layers and three planar single cell arrays, has a final height of $\sim 580 \mu \mathrm{m}$ measured by confocal laser scanning microscopy.

\section{Cell handling after laser printing}

For all reported quantitative analyses, the cells were treated in the following way:

A required amount of cells was printed. Direct after the printing process, the printed cells were rinsed off the collector slide with additional medium into a tube, counted, and reseeded into well plates for further analysis. The cells that remained on the donor slide underwent the same procedureexcept the laser printing - and were collected as control cells.

\section{Statistical analysis}

Statistical analyses of all data were carried out using the Student's unpaired two-sample $t$-test. $p$-Values of time series data are given as the minimum of the $p$-values obtained at different time moments.

\section{Results}

\section{Quantitative assessments of cell impairments}

To exclude possible alterations of cell behavior during the printing procedure, the survival rate, proliferation, and genotoxicity after laser printing were investigated. Compared with the nonprinted control cells, 99.7\% $\pm 0.6 \%$ (SEM) of ASCs and $97.8 \% \pm 3.1 \%$ of ECFCs (SEM) survived the laser printing procedure.

Further, the proliferation ability of the printed cells (ECFCs and ASCs) with respect to their nonprinted control has been assessed from four independent printing experiments per cell type over the time period of 11 days. The obtained results are shown in Figure $4 \mathrm{~A}$ and B. No differences in the proliferation of ECFCs $(p \geq 0.11)$ and ASCs $(p \geq 0.43)$ were registered. However, the cells may undergo external forces during the laser printing procedure leading to subcellular alterations, which cannot be visualized by the assessment of cell proliferation, for example, genotoxicity effects. To address this, DNA damage was measured by the comet assay method. Similar tail moments of printed ASCs (Printed: $2.07 \pm 0.22$; Control: $1.64 \pm 0.14$ [SEM]; $p=0.15$ ) and ECFCs (Printed: 1.53 \pm 0.16 ; Control: 1.26 \pm 0.11 [SEM]; $p=0.21$ ) with respect to their nonprinted control were observed.

\section{Cell numbers per droplet}

To characterize the amount of printed cells per droplet, $2 \times 10^{6}$ Calcein AM-stained ASCs were suspended in the HA-fibrinogen solution $\left(\eta=120 \mathrm{mPa}^{*} \mathrm{~s}\right)$. Afterward, an array of $5 \times 10$ droplets was printed and the number of cells in each droplet was counted, resulting in $52 \pm 14$ cells (mean \pm SD) per ejected droplet at a laser fluence of $3.7 \mathrm{~J} / \mathrm{cm}^{2}$. 
A

Ratio ECFC(green):ASC(red)

$1: 1$

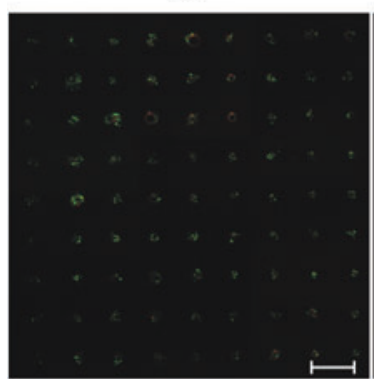

B

1

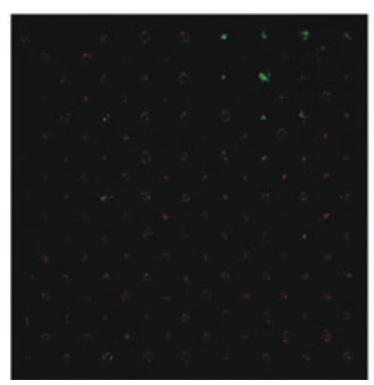

$2: 1$

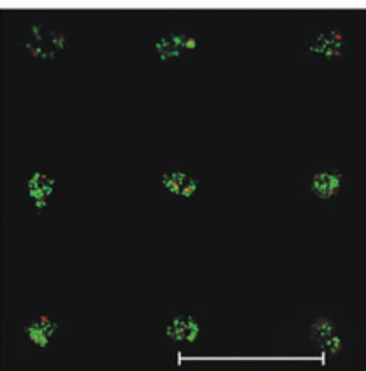

Iteration loops of printing

2

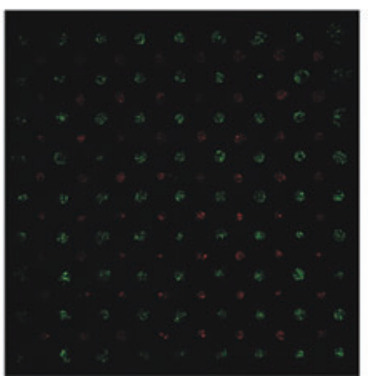

$4: 1$

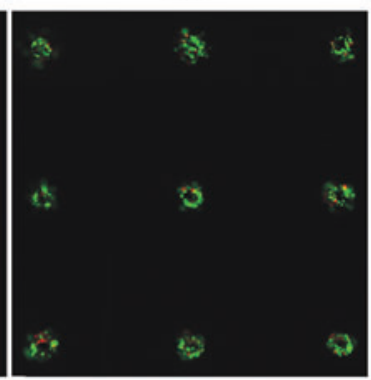

3

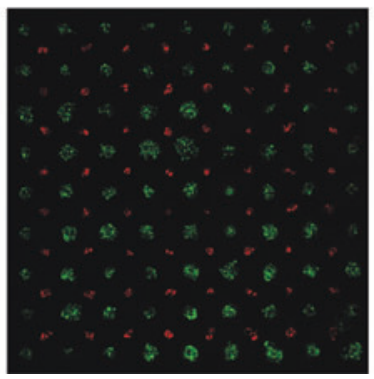

$8: 1$

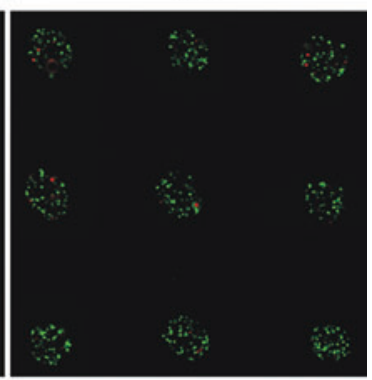

4

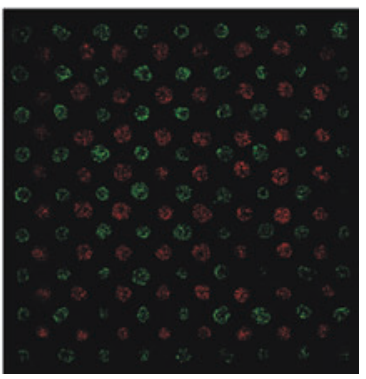

FIG. 2. Fluorescence images illustrating the variation of cell-cell ratios (A) and cell amounts (B) within the cell array. ECFCs were stained with calcein (green) and ASCs were stained with TAMRA-5 (red). Scale bars $=800 \mu \mathrm{m}$. ASC, adipose-derived stem cell; ECFC, endothelial colony-forming cell. Color images available online at www.liebertonline.com/tec
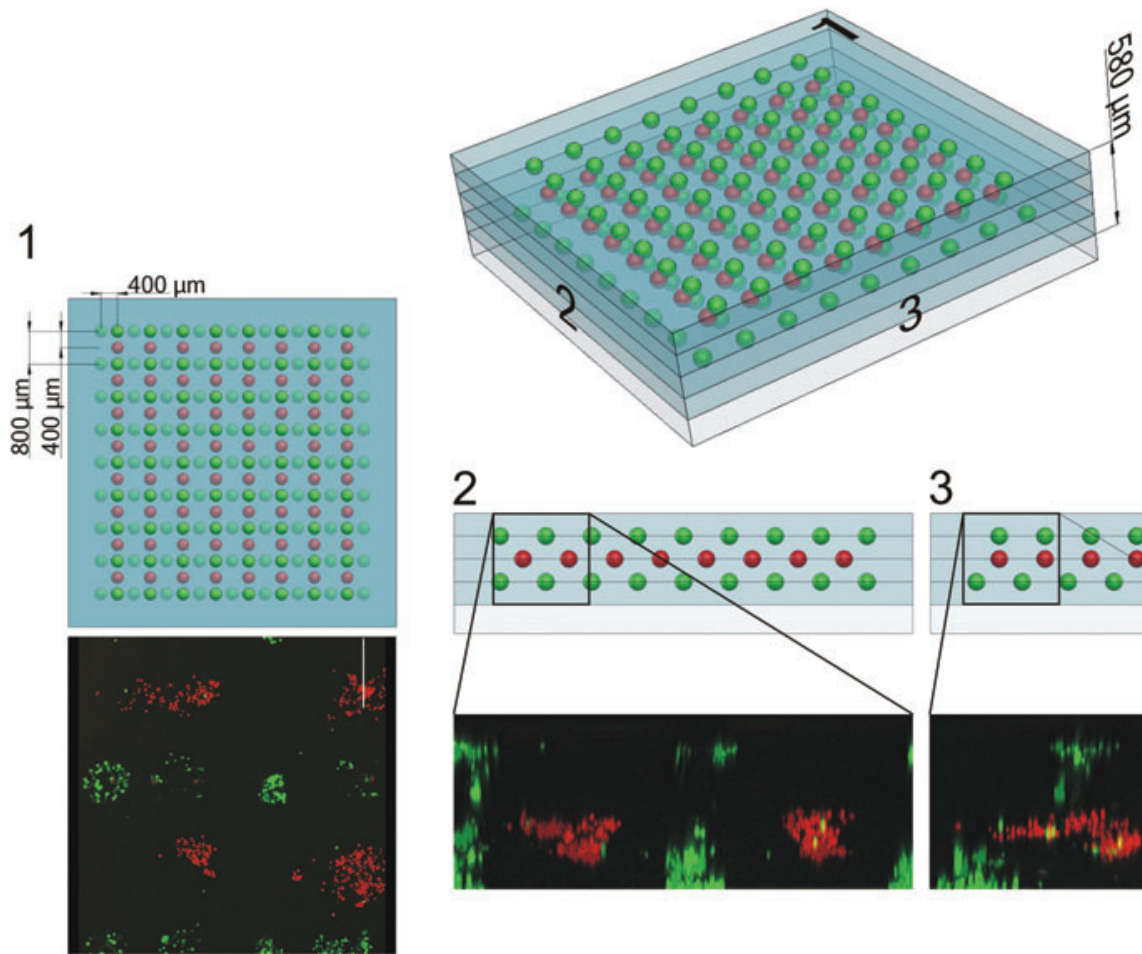

3

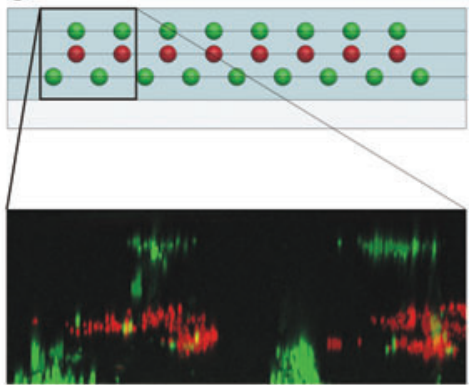

FIG. 3. Three-dimensional reconstruction of the 3D cell array by means of confocal laser scanning microscopy and the corresponding CAD model. ECFCs were stained with calcein (green) and ASCs were stained with TAMRA-5 (red). 3D, threedimensional. Color images available online at www.liebertonline.com/tec 
A

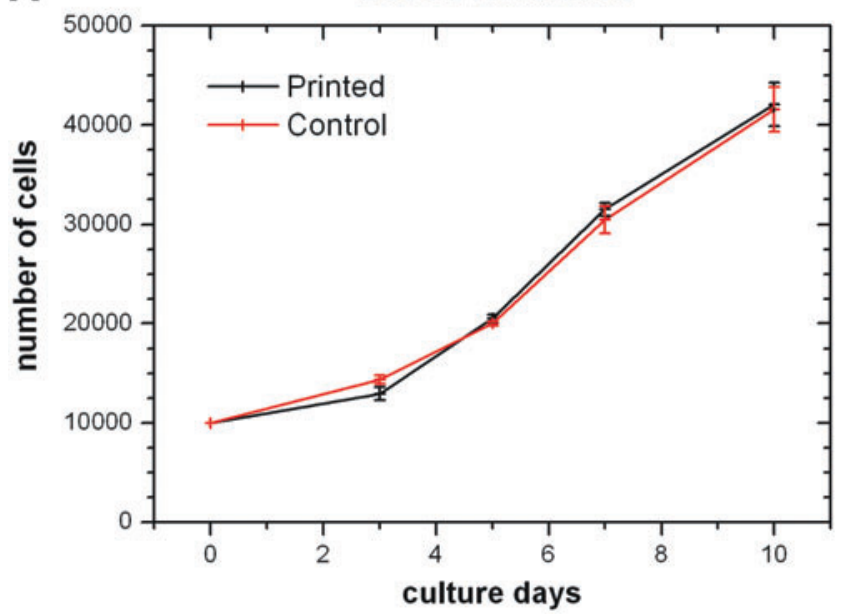

B

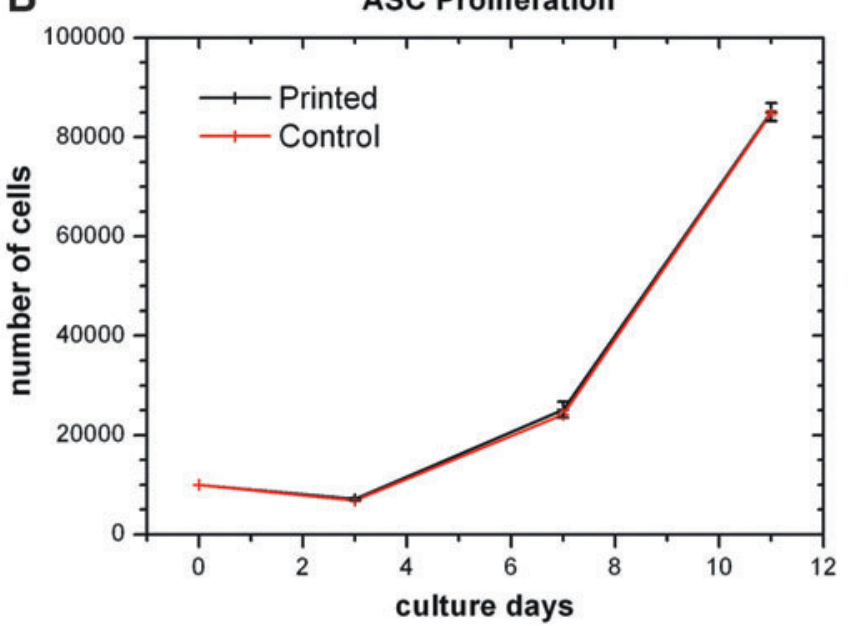

FIG. 4. Statistical assessment of proliferation ability from printed cells with respect to their nonprinted control. ECFCs (A) and ASCs (B) were counted with a Neubauer hemocytometer. Cell numbers are given as mean \pm standard error of mean $(n=4$ for all). Color images available online at www.liebertonline.com/tec

\section{Visualization of cell-cell interactions by the 3D cell array}

3D cell arrays with a planar spot distribution were generated and kept in VEGF-free medium for 10 days. Additionally, monoculture 3D cell arrays consisting of ASCs and ECFCs were generated and kept in VEGF-free culture medium as a control. In each case, four independent cell arrays were used.

To ensure that cell migration occurred only due to VEGF secretion by the ASCs and not due to residua in the applied medium, VEGF concentrations in each culture (ECFCs and ASCs) supernatant and the applied VEGF-free medium were determined. Here, the presence of VEGF was only demonstrated in the ASC culture supernatant $(\sim 2.5 \mathrm{ng} / \mathrm{mL}$ measured after $48 \mathrm{~h}$ incubation) by means of an enzymelinked immunosorbent assay (human VEGF ELISA Kit; RayBiotech, Inc.).

As shown in Figure 5, the ASC (+) migrated toward the ECFCs (o) and contacted them on day 3. Until this day the ECFCs showed negligible activity. After the cell-cell contacts became visible on day 3, the ECFCs began to form vascularlike networks, which grew out toward the ASC spots and formed big branches on day 7 of culture. The vascular-like network formation did not occur at the same time in all the four independent coculture cell arrays. However, we observed that between day 3 and 5 in VEGF-free culture medium, all cell arrays formed vascular-like networks. These networks remained stable for 2 weeks in culture (see Fig. 6) and were not observable either in the ASC control $(n=4)$ or the EC control $(n=4)$ as demonstrated in Figure 5.

\section{Discussion}

Delivering the right cue in space and time to the right cell is essential for the functional operation of tissue-engineered constructs. A detailed understanding of cell responses on external cues is crucial to make these effects predictable. Results obtained with adherent 2D cell cultures and/or cocultures cannot be generally transferred into 3D hydrogel cell cultures. ${ }^{44}$ Moreover, recent studies indicate that the local cell density, cellular spacing, cell-cell communication, and binding of cells to their 3D environment modulate and/or dictate cell behavior and tissue functionality. ${ }^{45-48}$ For further progress in this field, new methods for precise arrangement of different cell types in 3D with adjustable cell density and spacing as well as application of different hydrogel materials to mimic stimuli of native tissue environments are needed. One of these methods is LaBP. Among all bioprinting approaches, the flexibility of this orifice-free printing technique is truly unique. LaBP can handle various hydrogel precursors with a wide range of viscosities ${ }^{31,33,36-38}$ and the printed droplet volume carrying one to dozens of living cells can be adjusted in the range of $0.5-7000 \mathrm{pL}^{34,37,38,49}$

In this study, LaBP was used to generate 3D cell arrays to provide a proof of concept for imaging interactions between ASCs and ECFCs. Investigations of possible side effects that may be induced by the laser printing procedure are performed. By examining the viability, proliferation, and DNA fragmentation of printed cells compared with their nonprinted control, it is demonstrated that neither ASCs nor ECFCs are affected by the laser-assisted printing procedure. These findings confirm the results obtained by other groups with laser printing of different cell types, ranging from immortalized cell lines such as fibroblasts to various kinds of stem cells, where no alterations of the phenotype and genotype of the cells were observed. ${ }^{50}$ The flexibility of this approach by printing single or an arbitrary ratio of multiple cell types in spots is demonstrated. Spacing between the spots and the cell amount per spot can be independently controlled. In addition, even the fibrin-based environment that has been used in this article can be replaced by any other hydrogel, as it was previously demonstrated with Matrigel $^{\mathrm{TM}}{ }^{51}$ and alginate ${ }^{37}$ and recently with a removable gelatin-based gel. ${ }^{52}$

ASCs and ECFCs were chosen for investigation of vascular network formation, as recent studies indicate that these cell types represent suitable cell sources for therapeutic revascularization of ischemic tissues and can support new 
ASC

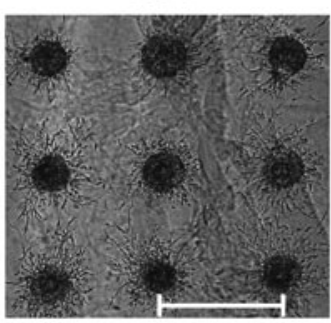

Day 3

Day 5

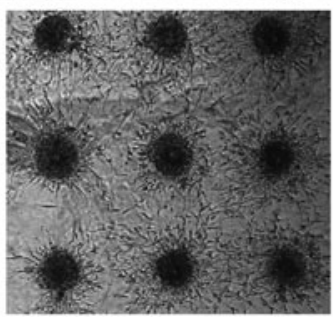

Day 7
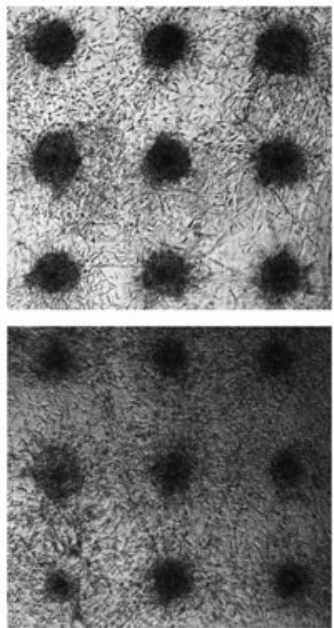

ECFC:ASC
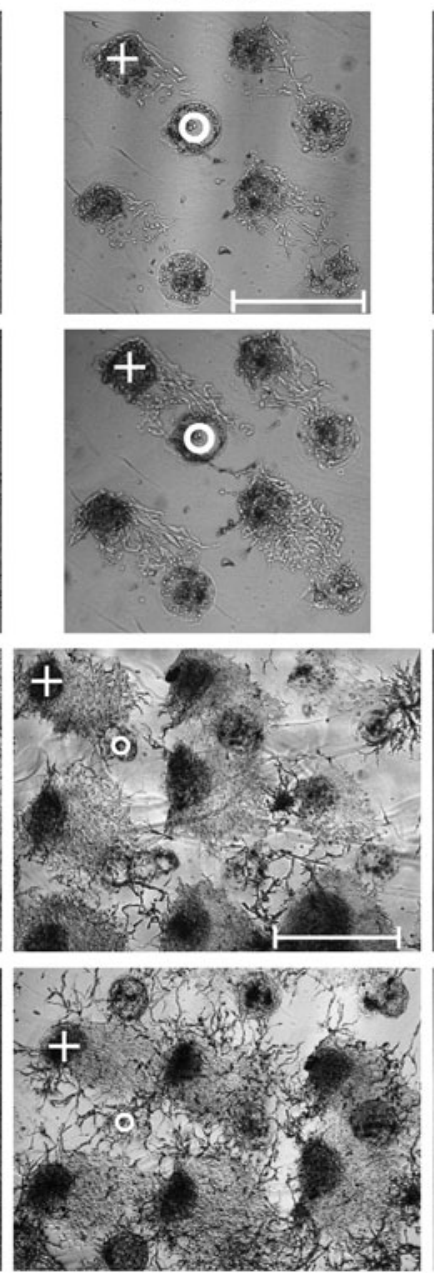
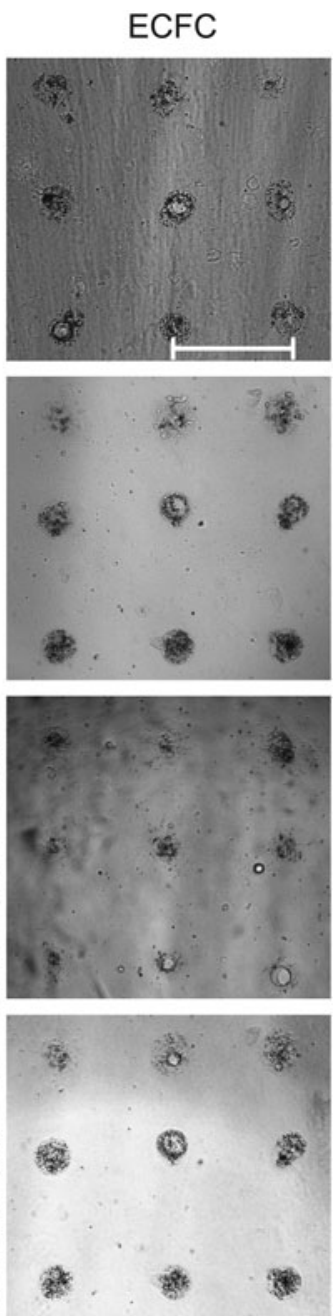

FIG. 5. Visualization of cellcell interactions by 3D cell arrays in mono- and cocultures. Interactions of ASCs and ECFCs in comparison to separated arrays of ASCs and ECFCs cultivated for 10 days under VEGF-free conditions. A circle indicates the printed ECFC spot and a cross indicates the printed ASC spot. Scale bars $=800 \mu \mathrm{m}$. VEGF, vascular endothelial growth factor. vessel formation in engineered tissue constructs. ${ }^{53,54}$ However, the exact mechanism by which ASCs and ECFCs support the formation of stable vascular networks remains unknown. So far it was assumed that direct cell-cell contacts and reciprocal signaling play an important role. ${ }^{19}$

Using the planar 3D cell array, we aimed to clarify that (i) cell-cell interactions lead to the development of stable vascular-like networks. This hypothesis was postulated by different workgroups over the last decade. ${ }^{19,53,55}$ Then, we planned to illustrate that (ii) the secretion of VEGF by the ASCs, which is well known for the promotion of endothelial cell proliferation, ${ }^{53}$ would lead to the outgrowth of ECFCs toward the ASCs along the VEGF gradient as it was reported by other groups. ${ }^{56,57}$ Interestingly, as demonstrated in Figure 5, the ECFCs showed only slight activity after $72 \mathrm{~h}$, whereas the activity of the ASCs was much more pronounced. However, after the ASCs contacted ECFCs between day 3 and 5, the activity of ECFCs strongly increased, resulting in the formation of a vascular-like network that remained stable for 2 weeks under culture conditions.

The observation that ASCs migrate toward ECFCs may be due to a gradient of platelet-derived growth factor (PDGF). The subtype PDGF-BB is expressed in large amounts by

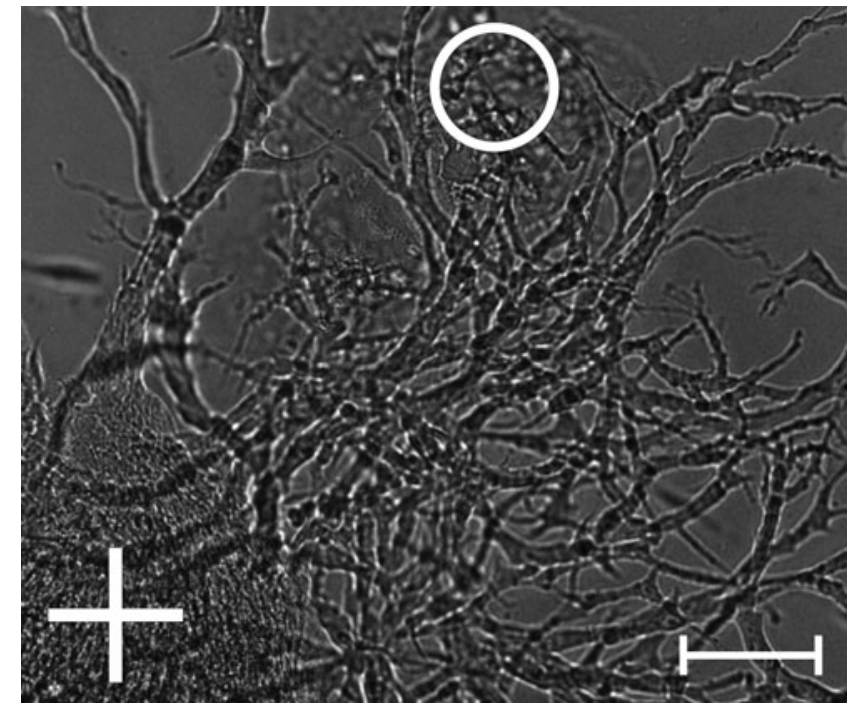

FIG. 6. Vascular-like network formation after 2 weeks under VEGF-free culture conditions. A circle indicates the printed ECFC spot and a cross indicates the printed ASC spot. Scale bar $=100 \mu \mathrm{m}$. 
ECFCs and is well known for the stimulation of ASC proliferation and migration. ${ }^{58}$ A PDGF-related effect by the HAfibrinogen layer can be excluded, because of the low amount of PDGF in fibrinogen solutions isolated from platelet-free plasma. ${ }^{59}$ However, as the molecular effects were not imaged in this work, further studies are needed to exclude or verify trigger signals, which are delivered when the cell-cell contact occurs. The flexibility of the 3D cell arrays presented here enables the identification and evaluation of these trigger signals.

\section{Conclusion}

In this study, we have presented a new method for visualizing cell-cell and cell-environment interactions using a fibrin-based layer-by-layer approach and an LaBP technique. Assessments of cell survival, proliferation, and cytotoxicity were conducted and possible negative effects caused by the printing procedure have been excluded. Within these 3D arrays, cell amount per spot, ratios between different cell types, and the spot-to-spot spacing can be arbitrary adjusted.

As a proof of concept, the interaction between ASCs and ECFCs has been studied resulting in the formation a vascular-like network.

Developmental processes and regenerative mechanisms in tissue engineering are based on upon molecular signals, direct cell-to-cell contact, and/or contact to ECM molecules. With the 3D cell arrays demonstrated in this publication, a new method that can be used to clarify correlations in the aforementioned fields is presented.

\section{Acknowledgments}

This work was supported by funding from the Deutsche Forschungsgemeinschaft (DFG, German Research Foundation) for the Cluster of Excellence REBIRTH (From Regenerative Biology to Reconstructive Therapy) and Sonderforschungsbereich Transregio 37 (Mikro- und Nanosysteme in der Medizin). The authors thank Prof. Dr. Kasper from the Institute for Technical Chemistry at the Leibniz University Hannover for providing FGF-2 and the BioMedimplant Lab for the access to the confocal laser scanning microscope.

\section{Disclosure Statement}

No competing financial interests exist.

\section{References}

1. Fernandes, T.G., Diogo, M.M., Clark, D.S., Dordick J.S., and Cabral J.M.S. High-throughput cellular microarray platforms: applications in drug discovery, toxicology and stem cell research. Trends Biotechnol 27, 342, 2009.

2. Yarmush, M.L., and King, K.R. Living-cell microarrays. Annu Rev Biomed Eng 11, 235, 2009.

3. Butte, A. The use and analysis of microarray data. Nat Rev Drug Discov 1, 951, 2002.

4. Bhadriraju, K., and Chen, C.S. Engineering cellular microenvironments to improve cell-based drug testing. Drug Discov Today 7, 612, 2002.

5. Flaim, C.J., Chien, S., and Bhatia, S.N. An extracellular matrix microarray for probing cellular differentiation. Nat Methods 2, 119, 2005.
6. Soen, Y., Mori, A., Palmer, T.D., and Brown, P.O. Exploring the regulation of human neural precursor cell differentiation using arrays of signalling microenvironments. Mol Syst Biol 2, 1, 2006.

7. Jones, C.N., Tuleuova, N., Lee, J.Y., Ramanculov, E., Reddi, A.H., Zern, M.A., and Revzin, A. Cultivating liver cells on printed arrays of hepatocyte growth factor. Biomaterials 30, 3733, 2009.

8. Anderson, D.G., Levenberg, S., and Langer, R. Nanoliterscale synthesis of arrayed biomaterials and application to human embryonic stem cells. Nat Biotechnol 22, 863, 2004.

9. Anderson, D.G., Putnam, D., Lavik, E.B., Mahmood, T.A., and Langer, R. Biomaterial microarrays: rapid, microscale screening of polymer-cell interaction. Biomaterials 26, 4892, 2005.

10. Cukierman, E., Pankov, R., and Yamada, K.M. Cell interactions with three-dimensional matrices. Curr Opin Cell Biol 14, 633, 2002.

11. Edelman, D.B., and Keefer, E.W. A cultural renaissance: in vitro cell biology embraces three-dimensional context. Exp Neurol 192, 1, 2005.

12. Ma, T., Grayson, W.L., Fröhlich, M., and Vunjak-Novakovic, G. Hypoxia and Stem Cell-based engineering of mesenchymal tissues. Biotechnol Prog 25, 32, 2009.

13. Lee, K.Y., and Mooney, D.J. Hydrogels for tissue engineering. Chem Rev 101, 1869, 2001.

14. Fedorovich, N.E., Alblas, J., Wijn, J.R.D., Hennink, W.E., Verbout, A.J., and Dhert, W.J.A. Hydrogels as extracellular matrices for skeletal tissue engineering: state-of-the-art and novel application in organ printing. Tissue Eng 13, 1905, 2007.

15. Albrecht, D.R., Underhill, G.H., Wassermann, T.B., Sah, R.L., and Bhatia, S.N. Probing the role of multicellular organization in three-dimensional microenvironments. Nat Methods 3, 369, 2006.

16. Akselrod, G.M., Timp, W., Mirsaidov, U., Zhao, Q., Li, C., and Timp, R. Laser-guided assembly of heterotypic threedimensional living cell microarrays. Biophys J 91, 3465, 2006.

17. Jongpaiboonkit, L., King, W.J., Lyons, G.E., Paguirigan, A.L., Warrick, J.W., Beebe, D.J., and Murphy, W.L. An adaptable hydrogel array format for 3-dimensional cell culture and analysis. Biomaterials 29, 3346, 2008.

18. Hui, T.Y., Cheung, K.M.C., Cheung, W.L., Chan, D., and Chan, B.P. In vitro chondrogenic differentiation of human mesenchymal stem cells in collagen microspheres: influence of cell seeding density and collagen concentration. Biomaterials 29, 3201, 2008.

19. Verseijden, F., Posthumus-van Sluijs, S.J., Pavljasevic, P., Hofer, S.O.P., van Osch, G.J.V.M., and Farrell, E. Adult human bone marrow- and adipose tissue-derived stromal cells support the formation of prevascular-like structures from endothelial cells in vitro. Tissue Eng Part A 16, 101, 2010.

20. Montano, I., Schiestl, C., Schneider, J., Pontiggia, L., Luginbühl, J., Biedermann, T., Böttcher-Haberzeth, S., Braziulis, E., Meuli, M., and Reichmann, E. Formation of human capillaries in vitro: the engineering of prevascularized matrices. Tissue Eng Part A 16, 269, 2010.

21. Xu, T., Kincaid, H., Atalana, A., and Yoo, J.J. Highthroughput production of single-cell microparticles using an inkjet printing technology. J Manuf Sci Eng 130, 021017, 2008. 
22. Xu, T., Jin, J., Gregory, C., Hickman, J.J., and Boland, T. Inkjet printing of viable mammalian cells. Biomaterials 26, 93, 2005.

23. Saunders, R.E., Gough, J.E., and Derby, B. Delivery of human fibroblast cells by piezoelectric drop-on-demand inkjet printing. Biomaterials 29, 193, 2008.

24. Nakamura, M., Kobayashi, A., Takagi, F., Watanabe, A., Hiruma, Y., Ohuchi, K., Iwasaki, Y., Horie, M., Morita, I., and Takatani, S. Biocompatible inkjet printing technique for designed seeding of individual living cells. Tissue Eng 11, 1658, 2005.

25. Wilson, W.C., and Boland, T. Cell and organ printing 1: protein and cell printers. Anat Rec Part A 272A, 491, 2003.

26. Di Biase, M., Saunders, R.E., Tirelli, N., and Derby, B. Inkjet printing and cell seeding thermoreversible photocurable gel structures. Soft Matter 7, 2639, 2011.

27. Chang, R., Nam, J., and Sun, W. Direct cell writing of 3D Microorgan for in vitro pharmacokinetic model. Tissue Eng Part C Methods 14, 157, 2008.

28. Mironov, V., Visconti, R.P., Kasyanov, V., Forgacs, G., Drake, C.J., and Markwald, R.R. Organ printing: tissue spheroids as building blocks. Biomaterials 30, 2164, 2009.

29. Chrisey, D.B. The power of direct writing. Science $\mathbf{2 8 9}, \mathbf{8 7 9}$, 2000.

30. Hon, K.K.B., Li, L., and Hutchings, I.M. Direct writing technology-advances and developments. CIRP Ann Manuf Technol 57, 601, 2008.

31. Barron, J.A., Krizman, D.B., and Ringeisen, B.R. Laser printing of single cells: statistical analysis, cell viability, and stress. Ann Biomed Eng 33, 121, 2005.

32. Ringeisen, B.R., Othon, C.M., Barron, J.A., Young, D., and Spargo, B.J. Jet-based methods to print living cells. Biotechnol J 1, 930, 2006.

33. Lin, Y., Huang, Y., and Chrisey, D.B. Droplet formation in matrix-assisted pulsed-laser evaporation direct writing of glycerol-water solution. J Appl Phys 105, 093111, 2009.

34. Gruene, M., Unger, C., Koch, L., Deiwick, A., and Chichkov, B. Dispensing pico to nanolitre of a natural hydrogel by laser-assisted bioprinting. Biomed Eng Online 10, 19, 2011.

35. Hopp, B., Smausz, T., Kresz, N., Barna, N., Bor, Z., and Kolozsvari, L. Survival and proliferative ability of various living cell types after laser-induced forward transfer. Tissue Eng 11, 1817, 2005.

36. Koch, L., Kuhn, S., Sorg, H., Gruene, M., Schlie, S., Gaebel, R., Polchow, B., Reimers, K., Stoelting, S., Ma, N., Vogt, P.M., Steinhoff, G., and Chichkov, B. Laser printing of skin cells and human stem cells. Tissue Eng Part C Methods 16, 847, 2010.

37. Gruene, M., Deiwick, A., Koch, L., Schlie, S., Unger, C., Hofmann, N., Bernemann, I., Glasmacher, B., and Chichkov, B. Laser printing of stem cells for biofabrication of scaffold-free autologous grafts. Tissue Eng Part C Methods 17, 79, 2011.

38. Guillotin, B., Souquet, A., Catros, S., Duocastella, M., Pippenger, B., Bellance, S., Bareille, R., Rémy, M., Bordenave, L., Amédée, J., and Guillemot, F. Laser assisted bioprinting of engineered tissue with high cell density and microscale organization. Biomaterials 31, 7250, 2010.

39. Gruene, M., Pflaum, M., Deiwick, A., Koch, L., Schlie, S., Unger, C., Wilhelmi, M., Haverich, A., and Chichkov, B.N. Adipogenic differentiation of laser-printed 3D tissue grafts consisting of human adipose-derived stem cells. Biofabrication 3, 015005, 2011.

40. Unger, C., Gruene, M., Koch, L., Koch, J., and Chichkov, B. Time-resolved imaging of hydrogel printing via laser- induced forward transfer. Appl Phys A Mater Sci Process 103, 271, 2010.

41. Duocastella, M., Fernández-Pradas, J.M., Morenza, J.L., and Serra, P. Time-resolved imaging of the laser forward transfer of liquids. J Appl Phys 106, 084907, 2009.

42. Hess, C., Wiegmann, B., Maurer, A.N., Fischer, P., Möller, L., Martin, U., Hilfiker, A., Haverich, A., and Fischer, S. Reduced thrombocyte adhesion to endothelialized poly 4Methyl-1-Pentene gas exchange membranes-a first step toward bioartificial lung development. Tissue Eng Part A 16, 3043, 2010.

43. Schlie, S., Ngezahayo, A., Ovsianikov, A., Fabian, T., Kolb, H.A., Haferkamp, H., and Chichkov, B.N. Three-dimensional cell growth on structures fabricated from Ormocer ${ }^{\circledR}$ by two-photon polymerisation technique. J Biomater Appl 22, 275, 2007.

44. Ma, T., Grayson, W.L., Fröhlich, M., and Vunjak-Novakovic, G. Hypoxia and stem cell-based engineering of mesenchymal tissues. Biotechnol Prog 25, 32, 2009.

45. Mauck, R.L., Seyhan, S.L., Ateshian, G.A., and Hung, C.T. Influence of seeding density and dynamic deformational loading on the developing structure/function relationships of chondrocyte-seeded agarose hydrogels. Ann Biomed Eng 30, 1046, 2002.

46. Tang, J., Peng, R., and Ding, J. The regulation of stem cell differentiation by cell-cell contact on micropatterned material surfaces. Biomaterials 31, 2470, 2010.

47. El-Ali, J., Sorger, P.K., and Jensen, K.F. Cells on chips. Nature 442, 403, 2006.

48. El-Amin, S.F., Lu, H.H., Khan, Y., Burems, J., Mitchell, J., Tuan, R.S., and Laurencin, C.T. Extracellular matrix production by human osteoblasts cultured on biodegradable polymers applicable for tissue engineering. Biomaterials 7, 1213, 2003.

49. Barron, J.A., Young, H.D., Dlott, D.D., Darfler, M.M., Krizman, D.B., and Ringeisen, B.R. Printing of protein microarrays via a capillary-free fluid jetting mechanism. Proteomics 5, 4138, 2005.

50. Schiele, N.R., Corr, D.T., Huang, Y., Raof, N.A., Xie, Y., and Chrisey, D.B. Laser-based direct-write techniques for cell printing. Biofabrication 2, 032001, 2010.

51. Schiele, N.R., Koppes, R.A., Corr, D.T., Ellison, K.S., Thompson, D.M., Ligon, L.A., Lippert, T.K.M., and Chrisey, D.B. Laser direct writing of combinatorial libraries of idealized cellular constructs: biomedical applications. Appl Surf Sci 255, 5444, 2009.

52. Raof, N.A., Schiele, N.R., Xie, Y., Chrisey, D.B., and Corr, D.T. The maintenance of pluripotency following laser directwrite of mouse embryonic stem cells. Biomaterials 32, 1802, 2011.

53. Merfeld-Clauss, S., Gollahalli, N., March, K.L., and Traktuev, D.O. Adipose tissue progenitor cells directly interact with endothelial cells to induce vascular network formation. Tissue Eng Part A 16, 2953, 2010.

54. Wu, Y., Chen, L., Scott, P.G., and Tredget, E.E. Mesenchymal stem cells enhance wound healing through differentiation and angiogenesis. Stem Cells 25, 2648, 2007.

55. Villars, F., Bordenave, L., Bareille, R., and Amédée, J. Effects of human endothelial cells on human bone marrow stromal cell phenotype: role of VEGF? J Cell Biochem 79, 672, 2000.

56. Mirsky, N., and Cohen, Y. VEGF and ECGF induce directed migration of endothelial cells: qualitative and quantitative assay. Endothelium 255, 5444, 1995. 
57. Akeson, A., Herman, A., Wiginton, D., and Greenberg, J. Endothelial cell activation in a VEGF-a gradient: relevance to cell fate decisions. Microvasc Res 80, 65, 2010.

58. Hellström, M., Kalén, M., Lindahl, P., Abramsson, A., and Betsholtz, C. Role of PDGF-B and PDGFR- $\beta$ in recruitment of vascular smooth muscle cells and pericytes during embryonic blood vessel formation in the mouse. Development 126, 3047, 1999.

59. Wirz, S., Dietrich, M., Flanagan, T.C., Bokermann, G., Wagner, W., Schmitz-Rode, T., and Jockenhoevel, S. Influence of PDGF-AB on tissue development in autologous platelet-rich plasma gels. Tissue Eng Part A 17, 1891, 2011.
Address correspondence to: Martin Gruene, Dipl.-Ing.

Department of Nanotechnology Laser Zentrum Hannover e.V.

Hollerithallee 8 30419 Hannover

Germany

E-mail: m.gruene@lzh.de

Received: March 30, 2011

Accepted: May 16, 2011

Online Publication Date: June 27, 2011 